Jurnal Pena Sains Vol. 5, No. 2, Oktober 2018

p-ISSN: 2407-2311

e-ISSN: 2527-7634

\title{
THE EFFECTIVENESS OF SCIENCE STUDENT WORKSHEET WITH COGNITIVE CONFLICT STRATEGIES TO REDUCE MISCONCEPTION ON HEAT CONCEPT
}

\author{
Heny Ekawati Haryono ${ }^{1)}$ \\ ${ }^{1}$ Mathematic Education Study Program, Universitas Islam Darul Ulum Lamongan East Java, \\ Indonesia \\ a) henny@unisda.ac.id
}

Accepted: August 27, 2018

Published: October 31, 2018

\begin{abstract}
This study aimed to determine the effectiveness of science worksheets with cognitive conflict strategies to reduce student heat misconceptions. This research was conducted at SMP Negeri 1 Lamongan by using one group pretest-posttest design. The data obtained in this study is quantitative data, and the number of students in VII grade is 50, students are called to complete the research if the proportion of correct answers is more significant than the standard achievement test. While the class is said to complete the study if $85 \%$ of students can reach the standard test criteria. The researcher obtained information about the level of mastery of students' concepts by using $N$-gain, one method in the descriptive qualitative analysis. It shows the different levels of student mastery before and after treatment given. The effectiveness of the Science Worksheet will be analyzed from the acquisition of learning outcomes. This yields 0.94 points which means that the value of N-Gain is in the sufficient category, it can be said that the application of the Science Worksheet with cognitive conflict strategies can reduce heat misconceptions of junior high school students.
\end{abstract}

Keywords: Cognitive Conflict Strategies, Misconception, Student Worksheet 


\section{Haryono}

\section{Introduction}

Physics is a fundamental science that forms the basis of the development of other sciences and technology. The growth of science and technology is very rapid nowadays, has made it easier for human life. Given the importance of the role of physics, this knowledge should be well understood by students. Learning physics is not just learning to deal with theories, formulas, and memorization. Learning physics must do something, experience and solve problems with all aspects related to it. One of the physics material students learn is heat. Heat material includes changes in the temperature of objects and the appearance of an object and the process of heat transfer.

It is often found that students who have followed the teaching and learning process have not shown optimal and enjoyable learning outcomes. Students answer the tests given different from the concepts that have been understood by scientists. The allegations that can be put forward are that students do not understand the concept well or students have a conception that is not in accordance with the actual concept (misconception) that causes students to experience difficulties in using the concepts they have to explain various natural phenomena. Heat material is an abstract material, because heat material involves a medium to know more clearly. Heat material requires a lot of understanding of concepts so as not to experience misconceptions in the understanding of heat concepts (Alwan, 2011).

The concept of learning physics is a very basic thing. Conceptual errors that have occurred in students will interfere with the effectiveness of learning and disrupt thinking students' in receiving the following knowledge. Students, who enter the class, are full of preconceptions about what the teacher will teach. The teacher does not realize and question the preconception and the students themselves are not aware of it. This suggests that before the teacher shows a new concept, the teacher must know that in the brain of the student there is a concept even though the facts are different.

Child's misconception is the main problem facing the world of education today. Misconceptions occur universally throughout the world regardless of their socio-cultural, linguistic and ethnic environment. Students' conceptions and misconceptions are strongly suspected to be formed during childhood in brain interaction with nature (Alwan, 2011). Studies of misconception indicate that misconceptions are resistant (Dilber and Duzgun, 2007). This happens because each builds his knowledge exactly with his experience (Elwan, 2007). Therefore, a teacher needs to understand the nature and characteristics of student misconceptions so that the teacher can prepare appropriate learning strategies to change students' misconceptions. Kang et al. (2007) state that it is easier to build students' knowledge from the beginning than to change knowledge that is a misconception. (Thomson, 2006) states that a student will be able to change the alternative concept if they begin to doubt the concept itself so that the correct concept proposed is useful. For that students must be confronted with different events that oppose the naïve concept of students who are often misconceptions. Therefore a learning strategy is needed that activates misconceptions. Learning strategies that activate student misconception are cognitive conflict learning strategies. 
Students tend to only listen to the teacher in conveying heat material and not directly involved in knowing the process of changing the temperature and form of an object and the process of heat transfer. Physics learning requires students to be able to understand the principles and concepts of physics from the simple to the complex. The ability to understand and connect the principles and concepts of physics that are taught with natural events in everyday life is important. Both of these can prevent misconceptions among students. Often such learning problems arise in class discussion opportunities that involve both individuals and between groups of students. Differences in views are the result of differences in understanding of principles and concepts known as cognitive conflict.

To overcome this misconception learning is done using science worksheets with cognitive conflict strategies accompanied by demonstrations and discussions so that the results of the evaluation of students' conceptual understanding tests conducted after learning have decreased the percentage of misconceptions for the main concept of the material. The percentage of completeness in the class has increased. This indicates that the teaching materials of Science student worksheet with cognitive conflict strategies have succeeded in reducing students 'misconceptions and increasing students' understanding of heat material. This shows that learning to use science student worksheet with cognitive conflict strategies is more effective than conventional learning.

Misunderstanding of concepts and misconceptions in students can be overcome with several concept changes. Strategies in the learning process, namely cognitive conflict. It based on student idea development and learning methods that can help change concepts. i.e. Bridging Analogy, computer simulations, diagnosis interviews, group discussion, concept map, problem-solving, experiment or field experience, questions in class continuously (Baser, 2006). According to the theory of constructivism, Piaget states when a person builds his knowledge, then to form a higher balance of science is needed adaptation (assimilation and accommodation), namely effective cognitive contact or conflict between old schemes/concepts and new reality (Thomson, 2006). Cognitive conflict strategy is a learning strategy that exposes students to situations that are contrary to the concept and then students are directed to experiments or demonstrations to prove the truth of the concept. Cognitive conflict strategy is a conceptual change strategy that can destabilize students' misconceptions towards the right scientific concept. So in this study, we want to do research entitled the effectiveness of Science student worksheet with Cognitive Conflict Strategies to Reduce Heat Misconceptions of Students of SMP Negeri 1 Lamongan.

\section{Research Method}

\section{Research design}

The activities undertaken during the development stage (stage 1) were to develop learning tools, composing instrument data collection, validation validator device, simulating a learning tool. While the activities carried out during the implementation phase (phase 2) in the form of implementation of learning using the first worksheet is the initial test (pre-test), the presentation of the subject matter, data collection, and a final test (post-test). In the final phase (phase 3) activities undertaken is an analysis of the data to conclude research results. 


\section{Haryono}

The Implementation of Classroom Learning Tools

The trials conducted using research designs One Group Pretest-Posttest Design is included in the experimental design. So the experimental results are the dependent variable not solely influenced by the dependent variable. This can occur, in the absence of a control variable, and the sample was not selected randomly (Kang, et al., 2010).

\section{$\mathrm{O} 1 \quad \mathrm{X} \quad \mathrm{O} 2$}

$\mathrm{O} 1$ is an initial test (pretest) to determine students' mastery of the subject matter before learning is done. $\mathrm{O} 2$ is a final test (post-test) to determine the mastery of subject students after learning is carried out $\mathrm{X}$ is the treatment of learning using science worksheets with cognitive conflict strategies that have been validated to reduce misconceptions of heat material on students of SMP Negeri 1 Lamongan.

\section{The Collection Data Method}

This research data collection method using the method of administration of the test which is performed twice, ie before the learning process begins and after the learning process. There is one kind of test that, THB (Test Results of Study). Achievement test product aims to regulate the cognitive aspects of student.

\section{Analysis Data Technique}

Data obtained in this research is quantitative data. The quantitative data obtained from the score of student competence which covers scores mastery of basic concepts of biology and its application in everyday life, whether cognitive performance scores of students. Mastery learning using descriptive analysis to determine student mastery learning (individual) can be calculated using percentages as follows: $\mathrm{KB}=\mathrm{S} / \mathrm{TS}$ $\mathrm{x} 100 \%$, where is $\mathrm{KB}$ is mastery learning;
$\mathrm{S}$ is the number of scores obtained by students; and TS is the total score.

Students are said to be complete learning (mastery people) if the proportion of correct answers students $\geq$ $75 \%$ (KKM), and a complete classroom learning (classical completeness) if within that class are $\geq 85 \%$ of students who have completed studies.

The data were analyzed with descriptive statistics. Statistical descriptions to answer research questions are only a statistical description of the average or percentage. To determine the student's mastery of concepts done using a qualitative descriptive analysis of $\mathrm{N}$ gain. Gain mastery showed differences or understanding of the concept of students before and after a given treatment.

\section{Results and Discussion}

Cognitive tests used to determine student learning outcomes as measured by the mastery of learning objectives. The purpose of learning is said to be complete when the proportion of correct answers students $(p) \geq 0.75$. Likewise, individual and classical completeness is said to be complete when $\geq 85$ percent of the students had thoroughly studied. The sensitivity and thoroughness of learning outcomes can see in the table 1 .

Table 1. Sensitivity items

\begin{tabular}{ccc}
\hline No & Items & Sensitivity \\
\hline 1 & 1 & 0,77 \\
2 & 2 & 0,66 \\
3 & 3 & 0,55 \\
4 & 4 & 0,44 \\
5 & 5 & 0,44 \\
6 & 6 & 0,66 \\
7 & 7 & 0,44 \\
8 & 8 & 0,55 \\
9 & 9 & 0,44 \\
10 & 10 & 0,44 \\
\hline \multicolumn{3}{c}{ Average } \\
\hline
\end{tabular}


Sensitivity is used to determine the effectiveness or influence of learning. Sensitivity values indicate the sensitivity of an item to measure the effect of teaching (Kang, et al., 2010). According to (Kang, et al., 2010), the sensitivity index of question items is between 0.00 and 1.00. The higher the positive $\mathrm{S}$ value for a test item, the more sensitive the test is to teach. From the table and graph above, we can see that the sensitivity level of the problem is 0.44 wherein item number 4, 5.9 and 10 . Whereas, the highest level of sensitivity is 0.77 in item number 1 . The average sensitivity is 0.539 . Question items that have sensitivity have sufficient sensitivity to the effects of learning. Sensitivity is used to determine the effectiveness or influence of learning. The effective item sensitivity index is from 0.00 to 1.00. The higher the sensitivity index shows, the higher the success of learning (see figure $1)$.

Based on the sensitivity of items, each item can be said to be sensitive to measuring learning effects because there are no items with negative sensitivity. This means that at the beginning of learning most students do not understand heat well so that misconceptions occur, but after learning using student worksheet with cognitive conflict strategies students better understand heat material, so they do not experience misconceptions and get better grades above KKM.

Development of Science Worksheets with cognitive conflict strategy with learning outcomes receives a score of 0.94 with High Gain scores. Based on the results of the response of positive students are interested in the learning process, so that the attitude of interest in causing students to try to learn more material, and the obtained material can be easy to understand and more embedded in students' memories. Some of these factors cause student learning outcomes to be completed. This is consistent with the suggestion that learning motivation, students achieve mastery can obtain high learning outcomes. Based on the sensitivity table items, all assessment items are sensitive learning outcomes. Questions about sensitive facilities to provide information that is the result of the assessment results, the lesson is oriented to the learning process skills. By the results Alwan (2011) it is said that the process of learning skills is better than conventional learning.

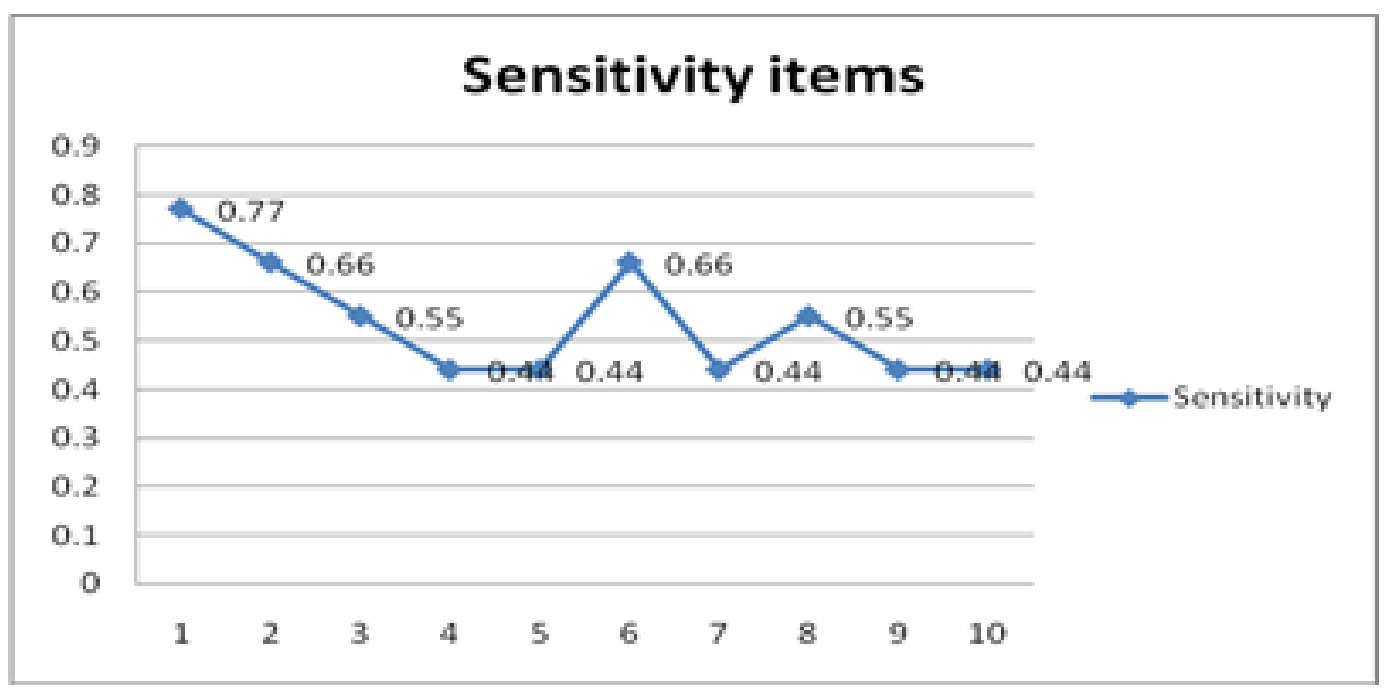

Figure 1. Sensitivity items 


\section{Haryono}

Table 2. The Completeness of Learning Outcomes

\begin{tabular}{|c|c|c|c|c|c|c|c|c|c|}
\hline \multirow[t]{2}{*}{ No } & \multicolumn{2}{|c|}{ Score } & \multicolumn{2}{|c|}{ Criteria } & \multirow[t]{2}{*}{ No } & \multicolumn{2}{|c|}{ Score } & \multicolumn{2}{|c|}{ Criteria } \\
\hline & Pretest & Post-test & Pretest & Posttest & & Pretest & Posttest & Pretest & Post-test \\
\hline 1 & 40 & 90 & TT & $\mathrm{T}$ & 26 & 30 & 100 & TT & $\mathrm{T}$ \\
\hline 2 & 50 & 100 & $\mathrm{TT}$ & $\mathrm{T}$ & 27 & 40 & 100 & TT & $\mathrm{T}$ \\
\hline 3 & 60 & 100 & $\mathrm{TT}$ & $\mathrm{T}$ & 28 & 30 & 100 & TT & $\mathrm{T}$ \\
\hline 4 & 40 & 100 & TT & $\mathrm{T}$ & 29 & 40 & 100 & TT & $\mathrm{T}$ \\
\hline 5 & 40 & 90 & $\mathrm{TT}$ & $\mathrm{T}$ & 30 & 30 & 90 & TT & $\mathrm{T}$ \\
\hline 6 & 30 & 100 & $\mathrm{TT}$ & $\mathrm{T}$ & 31 & 25 & 100 & TT & $\mathrm{T}$ \\
\hline 7 & 25 & 100 & TT & $\mathrm{T}$ & 32 & 25 & 90 & TT & $\mathrm{T}$ \\
\hline 8 & 50 & 100 & $\mathrm{TT}$ & $\mathrm{T}$ & 33 & 35 & 100 & TT & $\mathrm{T}$ \\
\hline 9 & 40 & 100 & $\mathrm{TT}$ & $\mathrm{T}$ & 34 & 25 & 95 & TT & $\mathrm{T}$ \\
\hline 10 & 35 & 90 & TT & $\mathrm{T}$ & 35 & 25 & 89 & TT & $\mathrm{T}$ \\
\hline 11 & 45 & 90 & TT & $\mathrm{T}$ & 36 & 30 & 90 & TT & $\mathrm{T}$ \\
\hline 12 & 40 & 90 & $\mathrm{TT}$ & $\mathrm{T}$ & 37 & 30 & 100 & TT & $\mathrm{T}$ \\
\hline 13 & 35 & 100 & TT & $\mathrm{T}$ & 38 & 25 & 95 & TT & $\mathrm{T}$ \\
\hline 14 & 40 & 95 & $\mathrm{TT}$ & $\mathrm{T}$ & 38 & 35 & 100 & TT & $\mathrm{T}$ \\
\hline 15 & 25 & 90 & TT & $\mathrm{T}$ & 40 & 25 & 100 & $\mathrm{TT}$ & $\mathrm{T}$ \\
\hline 16 & 30 & 90 & $\mathrm{TT}$ & $\mathrm{T}$ & 41 & 30 & 90 & TT & $\mathrm{T}$ \\
\hline 17 & 30 & 100 & $\mathrm{TT}$ & $\mathrm{T}$ & 42 & 25 & 90 & TT & $\mathrm{T}$ \\
\hline 18 & 40 & 95 & TT & $\mathrm{T}$ & 43 & 40 & 92 & $\mathrm{TT}$ & $\mathrm{T}$ \\
\hline 19 & 35 & 100 & $\mathrm{TT}$ & $\mathrm{T}$ & 44 & 25 & 100 & $\mathrm{TT}$ & $\mathrm{T}$ \\
\hline 20 & 25 & 100 & $\mathrm{TT}$ & $\mathrm{T}$ & 45 & 40 & 95 & $\mathrm{TT}$ & $\mathrm{T}$ \\
\hline 21 & 40 & 90 & TT & $\mathrm{T}$ & 46 & 25 & 90 & TT & $\mathrm{T}$ \\
\hline 22 & 50 & 100 & $\mathrm{TT}$ & $\mathrm{T}$ & 47 & 30 & 90 & TT & $\mathrm{T}$ \\
\hline 23 & 35 & 100 & TT & $\mathrm{T}$ & 48 & 30 & 100 & $\mathrm{TT}$ & $\mathrm{T}$ \\
\hline 24 & 40 & 100 & $\mathrm{TT}$ & $\mathrm{T}$ & 49 & 25 & 95 & $\mathrm{TT}$ & $\mathrm{T}$ \\
\hline 25 & 40 & 90 & $\mathrm{TT}$ & $\mathrm{T}$ & $\mathbf{5 0}$ & 40 & 100 & $\mathrm{TT}$ & $\mathrm{T}$ \\
\hline
\end{tabular}

$\mathrm{T}$ = Complete

$\mathrm{TT}=$ Uncomplete

Comparison between students' understanding of concepts in the heated material before and after learning with cognitive conflict strategies can be shown in Table 2. From the results of the pretest student analysis of answers given before learning with cognitive conflict, several heat concepts still have many misconceptions and conceptual incomprehension. The percentage of misconceptions and high understanding of concepts shows that students are trapped with the wrong understanding of their concepts so far. Examples of some heat-concept errors in students before being given learning with conflict strategies Differentiating Heat and Temperature, Determining heat capacity and heat of a type of substance, Determining the amount of temperature which is often considered to be related to the amount of 
matter (mass), Analyzing the effect of heat type on temperature changes. After learning with cognitive conflict strategies through data anomalies or examples of questions that conflict with the students' initial concepts accompanied by demonstrations, discussions, and experiments can have a substantial positive impact on changes in the understanding of the concept of heat in students. This can happen because in learning using science worksheets with cognitive conflict strategies students are required to express their concepts through demonstration activities in class. Besides, students discuss with teachers and classmates to clarify the correct concepts or misconceptions that exist during the demonstration.

Furthermore, the truth of the concept is reinforced through experiments carried out jointly by teachers and students. So that students' memory of the concepts given also becomes sharper. In this study, the concept of Distinguishing Heat and Temperature and Determining heat and heat capacity of a type of substance is a concept of vertical motion that is easily overcome by misconception problems. While the concept of determining the amount of temperature that is often considered to be related to the amount of material (mass) is a difficult concept to reduce the problem of misconceptions that exist in students. Difficulties in reducing student misconceptions and misunderstandings can be caused by old student schemes that are difficult to change (in assimilation or accommodation) in a short time. Besides, giving concepts without being accompanied by real experiments in learning can also be difficult in overcoming student misconceptions. There is, no perfect learning strategy; therefore we must be smarter in choosing learning strategies with environmental conditions, students and the material or concepts that will be taught. For example, in this study, there are several obstacles such as lack of time for class hours, because this cognitive conflict strategy tends to require a longer time. However, these problems can be overcome by adjusting the subject matter to be discussed with the length of lesson hours per meeting.

\section{Conclusion}

Research on the effectiveness of the use of science worksheets with cognitive conflict strategies to reduce class VII material misconceptions in SMP Negeri 1 Lamongan on learning outcomes in the cognitive domain has resulted in learning tools consisting of: (1) Lesson Plan, (2) student worksheet, (3) tests achievement. From the results of data analysis and discussion of the results of the study on the use of the effectiveness of the use of science worksheets with cognitive conflict strategies to reduce class VII material misconceptions in SMP N 1 Lamongan, it can be concluded that: learning using science worksheets with cognitive conflict strategies where high gain values are 0,94.

\section{Acknowledgment}

The authors thank to the Ministry of Research, Technology and Higher Education, due to the funding of PDP2018 for this work.

\section{References}

Alwan, A. (2011). "Misconception of heat and temperature among physics student". Procedia social and behavioral sciences. 12, pp 600-614.

Dilber, R. and Duzgun, B. (2007). “An investigation of the effectiveness of conceptual change textoriented instruction on student's understanding of brigthness concepts". Journal of science education - ProQuest education journals. 8. Pp. 46-52.

Duit, R. (2002). Conceptual change still a powerful frame for improving science teaching and learning. Paper presented in the 


\section{Haryono}

third European symposium on conceptual change, June 26-28. 2002, Turku, Finland.

Elwan, A. (2007). "Misconception in physics", Journal of Arabization, the Arab center for Arabization, translation authorship and publication, Damascus, pp 77103.

Kang, H. Scharman, L. C., Kang, S., and Noh, T. (2010). "Cognitive conflict and situational interest as factors influencing conceptual change". International journal of environmental \& science education. 5. PP. 383-405.

Başer, M. (2006) "Effect of conceptual change-oriented instruction on remediation of students misconceptions related to heat and temperature concepts," J. Maltese Educ. Res., 4, pp. 6479.

Sözbilir, M. (2003) "A review of selected literature on students' misconceptions of heat and temperature," Boğaziçi Univ. J. Educ., 20, pp. 25-41.

Tezcan, Nurhan \& Gamze. (2011). Misconceptions of science teacher candidate about heat and temperature. Procedia social and behavioral sciences. 15, 27592763.

Thomson, F.(2006)."An exploration of common student misconception in science". International education journal. 7, pp 553-559.

Trumper, R. (1990). "Being constructive: an alternative approach to the teaching of energy concept". International journal of science education.12, Pp. 343-354 